\section{JURNAL ABDIMAS

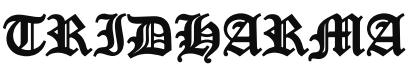

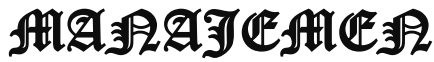

\title{
PEMANFAATAN LIMBAH GELAS AIR MINERAL SEBAGAI BAHAN DASAR BUNGA HIAS YANG CANTIK DAN MENARIK DI PKBM NEGERI 26 BINTARO JAKARTA SELATAN
}

\author{
Dewi Sartika, Aan Purnama, Riski Dwi Nugroho, Yusran Daeng Matta, M Restu Wijaya \\ Email* : dosen02208@unpam.ac.id, dosen02503@unpam.ac.id , \\ dosen02296@unpam.ac.id, dosen02231@unpam.ac.id, dosen02268@unpam.ac.id
}

\begin{abstract}
ABSTRAK
Pengabdian ini berjudul Pemanfaatan Limbah Gelas Air Mineral Sebagai Bahan Dasar Bunga Hias Yang Cantik Dan Menarik di Sekolah PKBM Bintaro Jakarta Selatan. Tujuan pengabdian ini adalah untuk membantu memberikan wawasan dan ide kreatif kepada anak anak di Sekolah PKBM Bintaro dalam hal memanfaatkan limbah gelas air mineral menjadi bunga hias yang cantik agar menambah daya jualnya sehingga diharapkan dapat menjadi tambahan penghasilan sehingga peserta didik disini dapat menjalani kehidupan yang lebih baik.

Metode pelaksanaan pengabdian ini dilakukan dalam beberapa kegiatan yaitu tahap survei yaitu sosialisasi dilakukan dengan menyusun berbagai hal yang akan disampaikan pada saat kegiatan pengabdian yang akan dilakukan yang meliputi: penyusunan materi yang akan diberikan, penyusunan jadwal pemberian materi, pembagian tugas tim pengabdian dan survei ke lokasi pengabdian. Tahap sosialisasi yaitu sebelum kegiatan pengabdian dilaksanakan terlebih dahulu dilakukan tahap sosialisasi yaitu melakukan silaturahmi dengan ketua yayasan, menyampaikan maksud dan tujuan pengabdian ini. Pada tahap ini juga dilakukan jalinan kerjasama dan menentukan jadwal kegiatan pengabdian. Tim pelaksana kegiatan pengabdian pada masyarakat adalah dosen Fakultas Ekonomi Jurusan Manajemen sebanyak 5 orang. Tim pengabdian memberikan materi tentang Pemanfaatan Limbah Gelas Air Mineral Sebagai Bahan Dasar Bunga Hias Yang Cantik Dan Menarik di PKBM Negeri 26 Bintaro Jakarta Selatan dan akan memberikan pelatihan disana oleh dosen UNPAM dan bekerja sama dengan Pembina Sekolah PKBM Negeri 26 Bintaro tersebut.

Kesimpulan dari pengabdian ini adalah peserta belum memiliki pengetahuan tentang bagaimana mengelola limbah gelas air mineral. Peserta juga belum mengetahui bagaimana cara membuat bunga hias yang cantik yang berasal dari limbah gelas air mineral tersebut. Harapan kami dengan pengabdian ini dapat membuka wawasan masyarakat yang diperoleh adalah bertambahnya keilmuan bagi para Para Masyarakat tentang proses pembuatan bunga hias cantik yang berasal dari limbah gelas air mineral yang sudah tidak terpakai dan Ilmu yang diperoleh pada Pengabdian Masyarakat kali ini diharapkan mampu memberikan semangat baru bagi kita dalam menyampaikan materi dan motivasi serta berkontribusi bagi generasi muda, baik di lingkungan sekolah, kampus dan keluarga
\end{abstract}

\section{Kata Kunci: Limbah Gelas Air Mineral, Bunga Hias Canti}

\begin{abstract}
This dedication is titled Utilization of Mineral Water Glass Waste as a Basic Material of Beautiful and Attractive Decorative Flowers in PKBM School Bintaro, South Jakarta
\end{abstract}




\section{JURNAL ABDIMAS

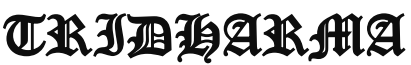 \\ AtA}

P-ISSN 2715-7105, E-ISSN 2716-070X

Jurnal ABDIMAS Vol. 1,No.2, Mei 2020, Hal (84-90)

@Prodi Manajemen Fakultas Ekonomi Universitas Pamulang

Email: abdimasjurnal.unpam@gmail.com Telp: (021) 741-2566

The purpose of this service is to help provide insight and creative ideas to children in the PKBM Bintaro School in terms of utilizing mineral water glass waste into a beautiful decorative flower in order to increase its selling power so that it is expected to be an additional income so that students here can live a better life. The method of implementing this service is carried out in a number of activities, namely the survey stage, namely the socialization carried out by arranging various things to be delivered at the time of service activities that will be carried out which include: preparation of material to be given, preparation of material delivery schedule, division of tasks of the service team and survey to the location devotion. The socialization phase is before the community service activities are carried out first, the socialization stage is to make a friendship with the chairman of the foundation, conveying the aims and objectives of this service. At this stage also carried out the fabric of cooperation and determine the schedule of service activities. The implementing team of community service activities is 8 people from the Faculty of Economics, Department of Management. The dedication team provided material on the Utilization of Mineral Water Glass Waste as a Basic Material of Beautiful and Attractive Decorative Flowers at the PKBM School in Bintaro, South Jakarta and will provide training there by UNPAM lecturers and in collaboration with the PKBM Bintaro School Trustees. The conclusion of this dedication is that Participants do not yet have knowledge about how to manage glass mineral water waste. The participants also did not know how to make beautiful ornamental flowers from the mineral water glass waste. Our hope with this dedication can open the community's insight gained is the increasing knowledge for the community about the process of making beautiful ornamental flowers that come from waste mineral water that has been unused and the knowledge gained in Community Service this time is expected to be able to provide new enthusiasm for we deliver material and motivation and contribute to the young generation, both in the school, campus and family environment

\section{Keywords: Mineral Water Glass Waste, Beautiful Decorative Flowers}

\section{PENDAHULUAN}

Limbah adalah buangan atau material sisa yang dianggap tidak memiliki nilai yang dihasilkan dari suatu proses produksi, baik industri maupun domestik (rumah tangga). Ada juga yang mengatakan bahwa definisi limbah adalah semua material sisa atau buangan yang berasal dari proses teknologi maupun dari proses alam dimana kehadirannya tidak bermanfaat bagi lingkungan dan tidak memiliki nilai ekonomis. Pada dasarnya berbagai jenis limbah dihasilkan oleh kegiatan manusia, baik itu kegiatan industri maupun domestik (rumah tangga) dan berdampak buruk terhadap lingkungan dan juga bagi kesehatan manusia. Dalam kajian SWI, dari $100 \%$ sampah plastik yang dihasilkan, $69 \%$ di antaranya masuk ke tempat pembuangan akhir dan hanya $7 \%$ yang didaur ulang.
Adapun 24\% mencemari lingkungan. Sampah plastik yang dibuang begitu saja sangat beragam, mulai dari barang rumah tangga sehari-hari hingga sedotan. Meski wujudnya kecil, sedotan untuk minuman kemasan gelas plastik belum banyak yang didaur ulang.

Di Indonesia sendiri, Danone-Aqua menyatakan akan merancang kemasan yang lebih mudah untuk didaur ulang. Perusahaan multinasional itu meneken kontrak kerja sama dengan perusahaan pengolahan sampah dari Perancis, Veolia, untuk membangun fasilitas daur ulang yang lebih canggih. Kerja sama dengan Veolia ini juga untuk memenuhi target meningkatkan proporsi plastik daur ulang dalam kemasan botol. Dari milestone di tahun 2020 targetnya adalah 25\%, jadi 2020 ini fasilitas yang dibuat vreolia ini akan 


\section{JURNAL ABDIMAS

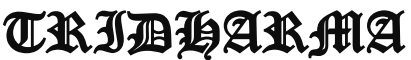

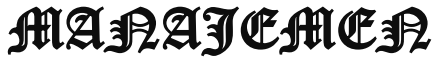

P-ISSN 2715-7105, E-ISSN 2716-070X

Jurnal ABDIMAS Vol. 1,No.2, Mei 2020, Hal (84-90)

@Prodi Manajemen Fakultas Ekonomi Universitas Pamulang

Email: abdimasjurnal.unpam@ gmail.com Telp: (021) 741-2566 selesai. Jadi kita bisa pakai $25 \%$ recycle terus bertahap kita naikkan sampai $50 \%$. Dewasa ini masalah sampah begitu pelik, pemandangan sampah telah menjadi pandangan kita sehari-hari. Namun belum juga mendapatkan jalan keluar yang terbaik dalam menangani masalah sampah ini. Teknologi begitu melaju dengan pesat namun penanganan dari sisa teknologi ini, khususnya sampah yang begitu sulit untuk terurai, yakni sampah berbahan plastik belum tertangani secara maksimal.

Setiap hari kita mengkonsumsi makanan dan minuman yang dibungkus oleh plastik, bungkus plastik tersebut biasanya hanya untuk sekali pakai saja, lalu dibuang. Hal itu menyebabkan limbah plastik bekas makanan maupun minuman di sekitar kita semakin meningkat. Bertambahnya jumlah sampah menyebabkan dampak yang cukup buruk kepada lingkungan. Sampah dalam bentuk plastik cukup susah diuraikan. Penelitian menunjukkan bahwa sampah plastik akan terurai dalam jangka waktu 50 juta tahun. Bayangkan, apabila hal ini tidak ditangani maka bumi akan menjadi tempat tinggal yang terbentuk dari sampah dan barang tidak berguna.

Berdasarkan uraian di atas, sudah seharusnya ada suatu cara untuk mengolah atau memanfaatkan limbah plastik bekas tersebut. Dalam pengolahannya, kita dapat memikirkan aspek ekonomisnya dan juga daya guna, agar kita terpicu untuk terus melakukan recycle atau mendaur ulang limbah plastik khususnya limbah kemasan gelas plastik untuk menyelamatkan eksistensi kebersihan bumi tercinta ini.

Untuk memanfaatkan peluang ini maka kami akan mensosialisasikan dan memberikan materi terkait Pemanfaatan Limbah Gelas Air Mineral Sebagai Bahan Dasar Bunga Hias yang Cantik dan Menarik di PKBM Negeri 26 Bintaro

\section{RUMUSAN MASALAH}

Dengan mempertimbangkan latar belakang yang telah dijelaskan diatas kami berinisiatif untuk membentuk pengabdian masyarakat bagi siswa dan siswi yang bersekolah di PKBM Negeri 26 Bintaro khususnya dalam program pelatihan agar dapat memanfaatkan limbah gelas air mineral sebagai bahan dasar bunga hias yang cantik dan menarik agar dapat menjadi salah satu kegiatan yang bermanfaat

Dalam program yang akan kami ajukan terdapat beberapa masalah yang perlu dirumuskan, antara lain sebagai berikut :

a. Bagaimana mengolah limbah gelas air mineral ?

b. Bagaimana cara membuat karya bunga hias yang berasal dari limbah gelas air mineral tersebut?

c. Bagaimana cara memasarkan hasil produk bunga hias tersebut?

\section{TUJUAN PELAKSANAAN}

1. Memberikan pengetahuan kepada siswa dan siswi PKBM Negeri 26 Bintaro mengenai cara mengurangi pengerusakan lingkungan oleh limbahlimbah rumah tangga

2. Memberikan salah satu solusi cerdas pengolahan limbah rumah tangga secara tegas.

3. Mengolah limbah rumah tangga menjadi barang yang berdaya guna

4. Memberikan pengetahuan kepada siswa dan siswi PKBM Negeri 26 Bintaro mengenai pemanfaatan limbah secara baik dan benar

\section{TINJAUAN PUSTAKA \\ 1. Pengertian Manajemen}

Pengertian manajemen secara umum dapat disimpulkan dari beberapa definisi menurut beberapa ahli. Hal ini dikarenakan banyak versi definisi manajemen. Contohnya saja manajemen menurut seorang ahli bernama Mary Parker Follet yang mendefinisikan manajemen sebagai seni merampungkan pekerjaan melalui orang lain. Dari definisi tersebut didapati bahwa seseorang yang bertugas sebagai manajer dapat mengarahkan dan mengatur orang lain guna mencapai tujuan 


\section{JURNAL ABDIMAS

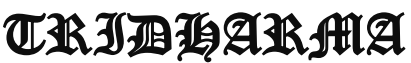

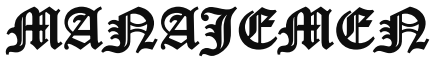

P-ISSN 2715-7105, E-ISSN 2716-070X

Jurnal ABDIMAS Vol. 1,No.2, Mei 2020, Hal (84-90)

@Prodi Manajemen Fakultas Ekonomi Universitas Pamulang

Email: abdimasjurnal.unpam@gmail.com Telp: (021) 741-2566
organisasi.Di sisi lain, James A.F Stoner mendefinisikan manajemen sebagai proses pengorganisasian, perencanaan dan penggunaan SDM supaya mencapai tujuan organisai yang sudah ditetapkan.

Secara umum, pengertian manajemen merupakan suatu seni dalam ilmu dan pengorganisasian seperti menyusun perencanaan, membangun organisai dan pengorganisasiannya, pergerakan serta pengendalian atau pengawasan. Bisa juga diartikan bahwa manajemen merupakan suatu ilmu pengetahuan yang sistematis agar dapat memahami mengapa dan bagaimana manusia saling bekerja sama agar dapat menghasilkan sesuatu yag bermanfaat bagi orang lain maupun golongan tertentu dn masyarakat luas.

Secara etimologis, pengertian manajemen merupakan seni untuk melaksanakan dan mengatur. Manajemen juga dapat dilihat sebagai ilmu yang mengajarkan proses mendapatkan tujuan dalam organisai, sebagai usaha bersama dengan beberapa orang dalam organisasi tersebut. Sehingga, ada orang yang merumuskan dan melaksanakan tindakan manajemen yang disebut dengan manajer.

\section{Fungsi Manajemen}

Pada dasarnya, fungsi manajemen dibagi menjai tiga, yaitu :

a. Perencanaan (planning)

Perecanaan adalah memikirkan apa yang akan dikerjakan dengan sumber yang dimiliki. Perencanaan dilakukan untuk menentukan tujuan perusahaan secara keseluruhan dan cara terbaik untuk memenuhi tujuan itu. Manajer mengevaluasi berbagai rencana alternative sebelum mengambil tindakan dan kemudian melihat apakah rencana yang dipilih cocok dan dapat digunakan umtuk memenuhi tujuan perusahaan. Perencanaan merupakan proses terpenting dari semua fungsi manajemen karena tanpa perencanaan, fungsi-fungsi lainnya tak dapat berjalan. b. Pengorganisasian (organizing)

Pengorganisasian dilakukan dengan tujuan membagi suatu kegiatan besar menjadi kegiatan-kegiatan yang lebih kecil. Pengorganisasian mempermudah manajer dalam melakukan pengawasan dan menentukan orang yang dibutuhkan untuk melaksanakan tugas-tugas yang telah dibagi-bagi tersebut. Pengorganisasian dapat dilakukan dengan cara menentukan tugas apa yag harus dikerjakan, siapa yang harus mengerjakan, bagaimana tugas-tugas tersebut dikelompokkan, siapa yang bertanggungjawab atas tugas tersebut, dan pada tingkatan mana keputusan harus diambil.

c. Pengarahan (directing)

Pengarahan adalah suatu tingakan untuk mengusahakan agar semua anggota kelompok berusaha agar dapat mencapai sasaran sesuai dengan perencanaan manajerial dan usaha.

Setiap perusahaan memiliki unsur-unsur untuk membentuk system manajerial yang baik. Unsur-unsur inilah yang disebut unsur manajemen. Jika salah satu diantaranya tidak sempurna atau tidak ada maka akan berimbas dengan berkurangnya upaya untuk mencapai tujuan.

\section{Pengertian Sampah Plastik}

Sampah menurut Undang-Undang Republik Indonesia No. 18 Tahun 2008 adalah sisa kegiatan sehari-hari manusia dan/atau proses alam yang berbentuk padat. Sampah adalah suatu benda yang tidak digunakan atau tidak dikehendaki dan harus dibuang, yang dihasilkan oleh kegiatan manusia (Karden Edy Sontang Manik, 2007).Sampah adalah suatu bahan yang terbuang atau dibuang dari sumber hasil aktivitas manusia maupun proses alam yang belum memiliki nilai ekonomis (Damanhuri, E., dkk., 2004).

\section{Pemanfaatan Limbah Plastik}

Pemanfaatan limbah plastik merupakan upaya menekan pembuangan plastik seminimal mungkin dan dalam batas tertentu menghemat sumber daya dan 


\section{JURNAL ABDIMAS

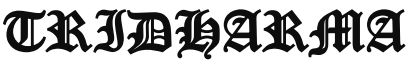

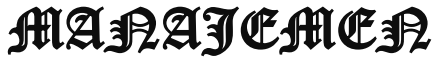

P-ISSN 2715-7105, E-ISSN 2716-070X

Jurnal ABDIMAS Vol. 1,No.2, Mei 2020, Hal (84-90)

@Prodi Manajemen Fakultas Ekonomi Universitas Pamulang

Email: abdimasjurnal.unpam@gmail.com Telp: (021) 741-2566 mengurangi ketergantungan bahan baku impor. Pemanfaatan limbah plastik dapat dilakukan dengan pemakaian kembali (reuse) maupun daur ulang (recycle). Di Indonesia, pemanfaatan limbah plastik dalam skala rumah tangga umumnya adalah dengan pemakaian kembali dengan keperluan yang berbeda, misalnya tempat cat yang terbuat dari plastik digunakan untuk pot atau ember. Sisi jelek pemakaian kembali, terutama dalam bentuk kemasan adalah sering digunakan untuk pemalsuan produk seperti yang seringkali terjadi di kota-kota besar.

Pemanfaatan limbah plastik di antaranya adalah untuk keperluan rumah tangga, atau sebagai bahan pembuat aksesoris maupun hiasan yang bisa dijadikan sebagai barang bernilai ekonomis. Plastik juga sudah banyak diwujudkan dalam bentuk busana, walaupun dalam presentasi kecil, contohnya seperti mantel, jas hujan, tas, aksesoris dan lain - lain. Hiasan dan korsase (dari plastik) akan memperindah busana kreasi baru dari bahan gelas plastik.

Pembuatan busana kreasi baru dari limbah gelas plastik seharusnya bernilai ekonomis tinggi. Akan tetapi, proses pembuatannya yang memerlukan waktu relatif lama terutama dalam mengecat gelas plastik sehingga diperlukan ketelitian dan kesabaran menjadi salah satu hambatan terwujudnya hal tersebut. Selain pemasangan hiasan gelas plastik.pada busana, kesulitan yang tampak terdapat pula pada pemeliharaan busana kreasi baru ini, selain ketelitian dengan penyimpananya diruang yang longgar/tidak sempit, menghindari udara lembab dan panas, serta secara periodik dikeluarkan guna dianginanginkan menjadi kaharusan untuk pemeliharaan busana. Selain itu, bahan baku limbah yang digunakan yang pada hakikatnya merupakan sampah yang tidak dipakai lagi mengharuskan biaya pengolahannya tidak termasuk dalam kisaran yang kecil.

\section{Hiasan dari Plastik}

Barang-barang bekas yang dijadikan karya seni ini adalah bentuk pemanfaatan, penghematan, dan gerakan untuk menjaga lingkungan. Banyak orang yang sering membuang barang-barang bekas ke tempat sampah, padahal sebagian masih dapat dimanfaatkan. Barang-barang ini sebenarnya layak untuk orang lain, oleh sebab itu kita harus jeli memanfaatkan barang tersebut.

Pemanfaatan barang bekas perlu dilakukan karena selain untuk menghemat, kita juga telah turut menjaga lingkungan. Tak ada rotan, akarpun jadi, begitulah bunyi salah satu peribahasa Indonesia yang mengandung makna dalam keadaan terpaksa, kita harus kreatif untuk bisa memecahkan masalah yang sedang dihadapi dengan menggunakan alat atau cara - cara yang tidak biasa. Peribahasa ini tepat digunakan untuk kesenian dari barang bekas, karena barang yang unik itu tidak hanya dibuat dengan menggunakan bahan dan teknologi yang tinggi, tetapi kita bisa memanfaatkan barang bekas dengan cara yang sangat sederhana.

Beberapa contoh barang bekas yang ada di sekitar kita, seperti plastik, bungkus sabun, bungkusan permen, kardus bekas, kertas bekas atau koran bekas, gelas retak, gelas plastik, sedotan minuman, benang, boneka, celengan, kaleng bekas, kapas dapat dimanfaatkan menjadi barang yang mempunyai nilai estetika. Berikut ini adalah contoh kerajinan dari limbah gelas plastik.

Kerajinan tangan dari limbah gelas plastik adalah kerajinan yang tidak asing bagi telinga kita. Banyak berbagai hasil kerajinan yang didapatkan. Dan yang paling sering dibuat adalah kerajinan tangan dalam bentuk bunga. Bunga plastik banyak yang bilang kalau bunga plastik itu bunga yang tidak memiliki harga karena terbuat dari plastik yang memang murah meriah, tetapi murah meriah itu tidak selalu barang yang tidak memiliki harga. Kerajinan ini sebenarnya kerajinan tangan yang sudah ada sejak jaman dahulu tetapi kerajinan dari 


\section{JURNAL ABDIMAS

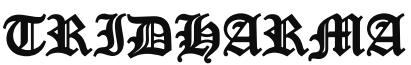

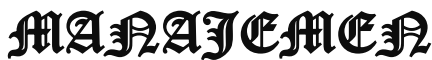

P-ISSN 2715-7105, E-ISSN 2716-070X

Jurnal ABDIMAS Vol. 1,No.2, Mei 2020, Hal (84-90)

@Prodi Manajemen Fakultas Ekonomi Universitas Pamulang

Email: abdimasjurnal.unpam@gmail.com Telp: (021) 741-2566

plastik ini masih dilakukan sampai sekarang.

\section{METODE PELAKSANAAN}

Metode pelaksanaan pengabdian ini dilakukan dalam beberapa kegiatan yaitu dengan survei kemudian menyusun berbagai hal yang akan disampaikan pada saat kegiatan pengabdian yang akan dilakukan. Kemudian tahap sosialisasi sebelum kegiatan pengabdian dilaksanakan dengan melakukan silaturahmi dengan ketua yayasan serta menyampaikan maksud dan tujuan dari pengabdian ini. Tim pelaksana kegiatan pengabdian pada masyarakat adalah dosen Fakultas Ekonomi jurusan Manajemen sebanyak 5 orang. Tim pengabdian memberikan pelatihan mengenai pemanfaatan limbah gelas air mineral sebagai bahan dasar bunga hias yang cantik dan menarik di PKBM Negeri 26 Bintaro Jakarta Selatan. Pelatihan ini dilaksanakan pada tanggal 24-26 Oktober 2019. Pelatihan ini bertujuan untuk memberikan tambahan pengetahuan bagi siswa/i di PKBM Negeri 26 Bintaro tersebut mengenai pengelolaan limbah plastik menjadi bernilai jual yang lebih tinggi.

\section{HASIL DAN PEMBAHASAN}

Pengabdian Kepada Masyarakat

(PKM) Universitas Pamulang dilakukan oleh dosen-dosen program studi Manajemen telah berjalan dengan lancer dan mendapat sambutan hangat dari para peserta kegiatan ini yaitu para siswa dari PKBM Negeri 26 Bintaro Jakarta Selatan.

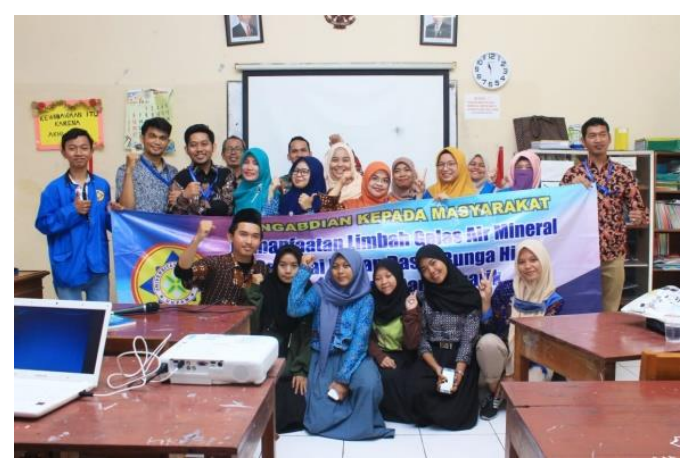

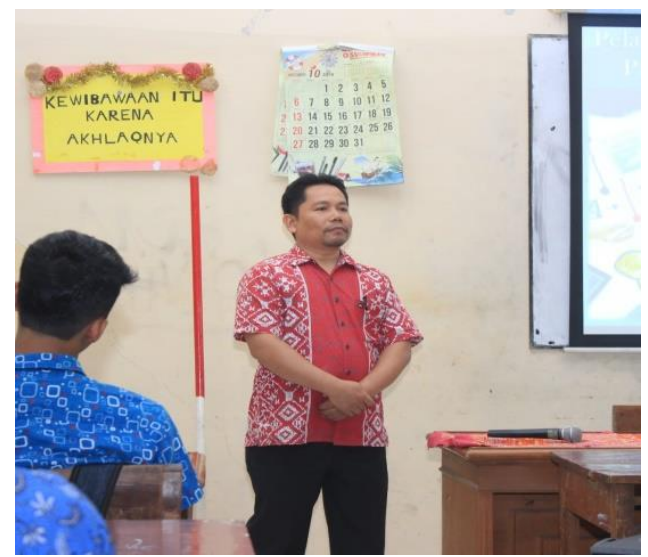

Harapan kami dengan pengabdian ini dapat menambah pengetahuan serta membuka wawasan dalam berwirausaha para siswa/i dari PKBM Negeri 26 Bintaro agar lebih memaksimalkan pemanfaatan limbah plastik menjadi benda dengan nilai jual yang lebih tinggi. Ilmu yang diperoleh dari Pengabdian Masyarakat ini diharapkan mampu memberikan semangat baru bagi kita dalam menyampaikan materi dan motivasi serta berkontribusi bagi generasi muda, baik di lingkungan sekolah, kampus dan keluarga.

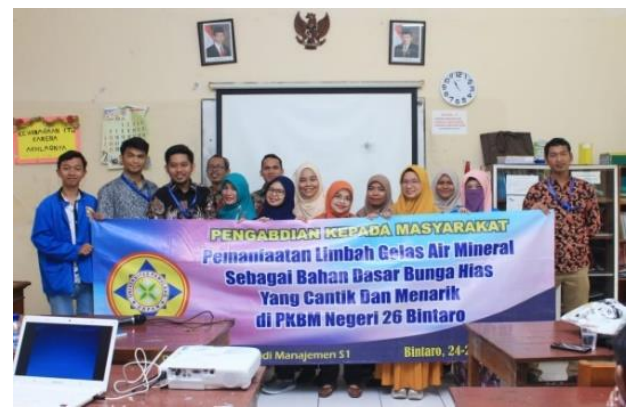




\section{JURNAL ABDIMAS P-ISSN 2715-7105, E-ISSN 2716-070X

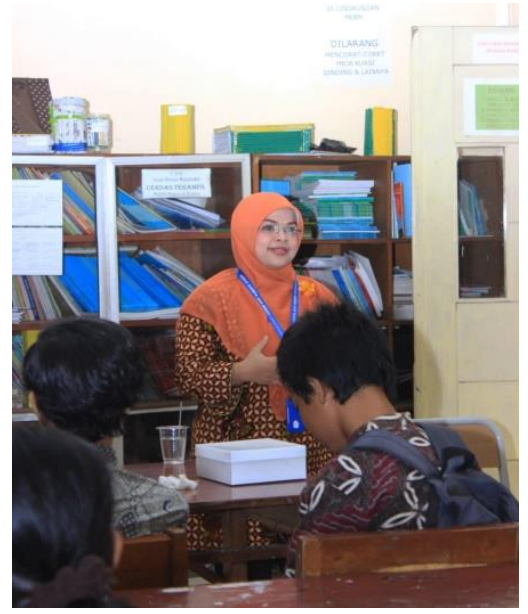

\section{KESIMPULAN DAN SARAN \\ Kesimpulan}

Dari kegiatan pengabdian pada masyarakat ini dapat disimpulkan bahwa:

1. Pengetahuan dan pemahaman siswa dan siswi PKBM Negeri 26 Bintaro tentang cara memanfaatkan limbah gelas air mineral menjadi bahan dasar pembuatan bunga hias yang cantik dan menarik menjadi meningkat.

2. Semakin meningkatnya jiwa wirausaha siswa dan siswi PKBM Negeri 26 Bintaro dengan memanfaatkan limbah gelas air mineral menjadi bahan dasar pembuatan bunga hias yang cantik dan menarik.

\section{Saran}

Mengingat besarnya manfaat kegiatan pengabdian pada masyarakat ini, maka selanjutnya perlu:

1. Mengadakan sosialisasi dan pelatihan serupa pada siswa sekolah lain di Kecamatan yang lain, dengan materi yang serupa.

2. Adanya kesinambungan program pasca kegiatan pengabdian ini sehingga para siswa benar-benar dapat memanfaatkan limbah gelas air mineral menjadi bahan dasar pembuatan bunga hias yang cantik dan menarik.

\section{DAFTAR PUSTAKA}

Aminudin dan Nurwati. 2019. Pemanfaatan Sampah Plastik Menjadi Kerajinan Tangan Guna Meningkatkan Kreatifitas Warga Sekitar Institut Teknologi dan Bisnis Ahmad Dahlan (ITBAD) Jakarta. JURNAL ABDIMAS BSI Jurnal Pengabdian Kepada Masyarakat Vol. 2 No. 1 Februari 2019, Hal. 66-79 E-ISSN : 2614-6711 66

Doriza, Shinta dan Vera Utami Gede Putri. 2017 Pemanfaatan Limbah Botol Plastik Melalui Pelatihan Wirausaha Produk Aksesoris Bagi Ibu Rumah Tangga. Jurnal Sarwahita Volume 11 No. 2

Hasibuan, S.P Malayu, 2002, Organisasi dan Motivasi : Dasar Peningkatan Produktifitas, Jakarta: Bumi Aksara

Hozairi, Achmad. Pemanfaat Limbah Gelas Plastik Air Mineral Sebagai Bahan Ukir Bertemu Kehidupan Anak Jalanan. 2017. Jurnal Pendidikan Seni Rupa, Volume 05 Nomor 01 Tahun 2017, 19-26

Putra, Hijrah Purnama dan Yebi Yuriandala. 2010. Studi Pemanfaatan Sampah Plastik Menjadi Produk dan Jasa Kreatif. Jurnal Sains dan Teknologi Lingkungan Volume 2, Nomor 1, Januari 2010, Halaman 21-31. ISSN : 2085-1227

Seizaria, Silkyane. 2017.

Eksplorasi Limbah Gelas Plastik Untuk

Diterapkan Pada Produk Fesyen. e-

Proceeding of Art \& Design : Vol.4, No.3

Desember 2017 | Page 941

ISSN : 2355-9349

Sugiyono. (2013). Metode Penelitian Pendidikan. Bandung: Alfabeta. 